\title{
On Utilization of Elliptical Rings in Assessing Cracking Tendency of Concrete
}

\author{
Xiangming Zhou, Olayinka G. Oladiran, and Wei Dong \\ School of Engineering and Design, Brunel University
}

\begin{abstract}
A new experimental method by utilizing elliptical rings to replace circular rings recommended by ASTM and AASHTO was explored for assessing cracking potential of concrete and other cement-based materials under restrained condition. A series of thin and thick elliptical concrete rings were tested alongside circular ones until cracking. Cracking age, position, and propagation were carefully examined. It is found that thin elliptical rings with appropriate geometry can initiate cracks quicker than circular ones, which is desirable for accelerating the ring test. However, thick elliptical rings seem not to exhibit a desirable geometry effect of accelerating ring test compared with circular ones. There were multiple visible cracks that occurred in an elliptical ring and some cracks were initiated but did not propagate through the ring wall. In comparison, there was only one crack in the circular rings. Finally, the features of multiple cracks in restrained elliptical rings were examined and their impact on interpreting elliptical ring test results was elaborated.
\end{abstract}

\section{INTRODUCTION}

The complexities of early-age cracking of concrete and other cement-based materials are yet to be fully understood. Over the years, cracking has led to premature deterioration, which effectively shortens the service life of concrete structures and presents a potential hazard to their safety and serviceability. Volume of concrete changes in response to moisture and/or temperature variation as well as chemical reaction of cement, and if restrained, it will result in stress development that may finally lead to cracking once the developed tensile stress exceeds the tensile strength of concrete. In light of this, the role of concrete shrinkage as it affects this serviceability behavior (i.e., cracking) should not be neglected. Nevertheless, the extent of shrinkage is indeed the driving force for early-age cracking of concrete, but whether cracking will occur or not is also dependent on the restraint in the structure and the stress relaxation, which may be particularly high in early-age concrete. Such undesirable phenomenon undoubtedly reduces the load-carrying capacity of concrete members and indeed accelerates deterioration, hence yielding premature failure. For structures like tanks or nuclear containment vessels, this cracking may significantly increase concrete permeability and reduce tightness as well as structural integrity. For massive structures (e.g., bridges, dams, and tunnels), their serviceability performance may be reduced due to penetration of aggressive species (such as carbon dioxide, sulfate, and chloride ions; Briffaut, Benboudjema, Torrenti, \& Nahas, 2011), which further leads to corrosion of reinforcement bars embedded in concrete.
Over the years, a number of test methods have been developed to assess how susceptible a given concrete mixture may be to cracking. Although free shrinkage measurements are useful in comparing different mix proportions, they do not provide sufficient information to determine how concrete will crack in service (Shah, Weiss, \& Yang, 1998). Rather, cracking tendency of concrete is mainly evaluated under restrained conditions by qualitative means through a variety of cracking tests, such as the beam, the plate, and the ring tests, among which the circular ring test has been developed for such purposes due to its simplicity and versatility (Moon \& Weiss, 2006). The circular ring test method has been used by various researchers for investigating cracking potential of concrete or other cement-based materials under restrained conditions (Bentur \& Kovler, 2003). So far, these researches have been basically concentrated on three fields, namely, the effects of concrete mixture compositions ( $\mathrm{Li}, \mathrm{Qi}, \mathrm{Li}, \& \mathrm{Ma}, 1999$; Mokarem, Weyers, \& Lane, 2005; Passuello, Moriconi, \& Shah, 2009; See, Attiogbe, \& Miltenberger, 2003; Tongaroonsri \& Tangtermsirikul, 2009; Turcry, Loukili, Haidar, Pijaudier-Cabot, \& Belarbi, 2006), moisture gradients, and drying conditions (Branch, Rawling, Hannant, \& Mulheron, 2002; Hossain \& Weiss, 2004, 2006; Moon, Rajabipour, Pease, \& Weiss, 2006; Moon \& Weiss, 2006; Weiss \& Shah, 2002; Weiss, Yang, \& Shah, 2000) and ring size and geometry (Hossain \& Weiss, 2006; Moon et al., 2006; Moon \& Weiss, 2006). Effectively, the restrained circular ring test has become a standard method recommended by American Association of State Highway and 
Transportation Officials (AASHTO) PP34-99 (2005): Standard Practice for Estimating the Cracking Tendency of Concrete using circular ring specimens with the concrete wall thickness of $76 \mathrm{~mm}\left(3^{\prime \prime}\right)$ referred to as thick rings in this study and by American Society of Testing and Materials (ASTM) C1581/C1581M09a: A Standard Test Method for Determining Age at Cracking and Induced Tensile Stress Characteristics of Mortar and Concrete under Restrained Shrinkage using circular ring specimens with the concrete wall thickness of $38 \mathrm{~mm}\left(1.5^{\prime \prime}\right)$ referred to as thin rings in this study, to shorten the circular ring test duration. In both standards, strain gages are used to measure strain of the central restraining steel core to provide a more accurate assessment of cracking age as compared to simple visual observation of the time-tofirst-cracking, which is useful but maybe less reliable than strain monitoring. In practice, the circular ring test is also widely used to determine the effects of material variations on cracking potential of concrete mixtures as well as on induced tensile stress in restrained concrete. These variations may include aggregate source, aggregate gradation, cement type, cement content, water content, fiber reinforcement, supplementary cementitious materials, and chemical admixtures. However, the circular ring test methods recommended by ASTM and AASHTO have been noted to have a low degree of restraint, resulting in a fairly long time before the first crack initiates (Bentur \& Kovler, 2003; Moon et al., 2006). It is also regarded to have a low cracking sensitivity and not efficient for large amounts of material evaluation (See et al., 2003). In addition, because the degree of restraint is largely dependent on stiffness and geometry of the central restraining steel ring, concrete in a circular ring test may not develop a visible crack if the steel ring is not thick enough (Hossain \& Weiss, 2006), that is, the restraining stiffness of the steel core is not big enough. Meanwhile, due to geometry effect, there is an equal opportunity of the crack occurring along the circumference of a circular concrete ring, so that it is not possible to predict the exact position of the crack.

Therefore, in a bid to overcome the problems from traditional circular ring tests and to improve the ability of generating a visible crack within a shorter period, a novel elliptical ring geometry was adopted by $\mathrm{He}$, Zhou, and $\mathrm{Li}$ (2004) the first time when investigating the effect of alkali on early-age cracking properties of cementbased materials. It was believed by them that for the sake of promoting crack initiation and determining cracking sensitivity in a shorter period, the elliptical geometry is more effective in evaluating early-age cracking properties for mortar and concrete (He et al., 2004). It was also expected that, unlike the circular ring specimens, the first cracking is concentrated at certain positions depending on the elliptical ring geometry and will largely reduce instruments and resources needed for detecting crack initiation and propagation in the ring test. Nevertheless, their efforts did not include comparing cracking tendencies in the circular rings in relation to the newly developed elliptical rings. Rather it was believed, without solid scientific evidence, that cracking initiation can be accelerated by the elliptically shaped rings due to stress concentration. It should be noted, however, that the circumferential stress in an elliptical ring specimen is different along its circumference because the degree of restraint provided by the central elliptical restraining steel core is different along its circumference. This is the main difference from the case with a circular ring specimen in which the circumferential stress is uniform along its circumference. Meanwhile, the degree of restraint is believed to be sensitive to the geometry of the central restraining steel ring, especially the major and minor semi-axes of its outer elliptical circumference, which have the most significant effect on initial cracking age and position of concrete elliptical rings under restrained shrinkage. Because of this, characterizing cracking sensitivity of concrete is able to be achieved within a shorter period so that the new elliptical ring test could replace the traditional circular ring test for faster assessment of cracking potential of concrete and other cement-based materials. However, there is no research published so far on comparing circular and elliptical ring test for assessing the relative likelihood of cracking of concrete. Neither is there any study reported on the cracking behavior of thin and thick ring specimens made from the same concrete mixture under the same restrained condition. In fact, as aforementioned, there are two standard circular ring test methods, one published by AASHTO recommending thick concrete ring specimens with a wall thickness of $76 \mathrm{~mm}\left(3^{\prime \prime}\right)$ and the other by ASTM, suggesting thin concrete ring specimens with a wall thickness of $38 \mathrm{~mm}\left(1.5^{\prime \prime}\right)$. It comes that there is limited research published on the effect of ring wall thickness on cracking of concrete under restrained shrinkage, for not only elliptical rings but also circular rings. It was therefore another objective of this article to investigate the effect of concrete wall thickness on cracking behavior of concrete ring specimens under restrained shrinkage so as to recommend the better one for practical usage. In addition, this study will investigate how an elliptical ring specimen with a simple geometry can provide information to enable an improved understanding of shrinkage cracking and better evaluation of cracking tendency of concrete and other cement-based materials. Moreover as a test method for assessing cracking potential of concrete mixtures, the ability to generate a visible crack within a shorter period is desirable for large amounts of assessment of cracking tendency of concrete materials. This study therefore 
proposed a novel, faster, and reliable test method for assessing cracking potential of concrete, which may be attributed to the elliptical geometry adopted.

\section{EXPERIMENTAL}

\subsection{Raw materials and mix proportions}

The mix proportions for the concrete mixture investigated in this article were 1:1.5:1.5:0.5 (cement:sand:coarse aggregate:water) by weight, which represents a therapy of normal strength concrete. Commercially available CEM II Portland cement (from LAFARGE Cement UK) conforming to EN 197-1 was used as binder for preparing concrete. The specific gravity density of the CEM II Portland cement was 2.96 with Blaine fineness (specific surface area) of $423 \mathrm{~m}^{2} / \mathrm{kg}$ measured conforming to EN 196-6. River sand with 2-mm maximum grain size and fineness modulus of 3.27 , measured conforming to EN 12620, was used as fine aggregates. Gravel stone with $10-\mathrm{mm}$ maximum particle size was used as coarse aggregates. Both fine and coarse aggregates were pre-treated in an oven at the temperature of $105^{\circ} \mathrm{C}$ for $24 \mathrm{~h}$ to eliminate any moisture assimilated prior to material preparation. They were then cooled down in air for $2 \mathrm{~h}$ before being used for concrete mix. Concrete was prepared using a drum-type concrete mixer.

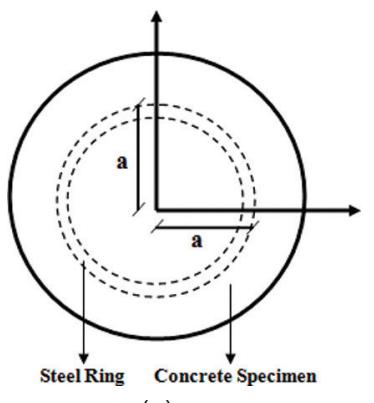

(a)

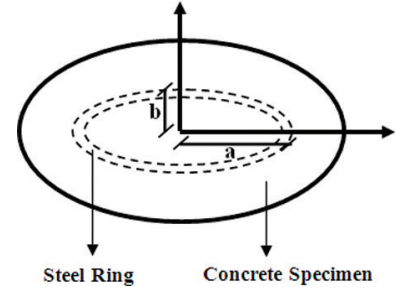

(b)
Figure 1. Notations of geometries of ring specimens. (a) Circular ring. (b) Elliptical ring.

\subsection{Ring geometry}

Although higher degree of restraint can be achieved by increasing the wall thickness of the central restraining steel ring, which consequently results in higher stress developed in concrete, the elliptical ring test exhibits a different behavior. In this case, however, the degree of restraint is regarded largely depending on the geometrical factor $a / b$, in which $a$ and $b$ represent the major and minor principle semiaxes of a central restraining steel ring's external circumference, respectively (see Figure 1), which coincide with the major and minor principle semiaxes of the inner circumference of the concrete ring specimen. However, it should be noted that in case of an elliptical shape, the degree of restraint along the circumference provided by the central steel core is not uniform due to geometrical effect. Illustratively, the steel ring acts as a restraint to the concrete ring surrounding it when concrete shrinks. As a result, compressive stress is induced in the steel ring and tensile stress in the concrete ring. Once the developed tensile stress in concrete exceeds its tensile strength, cracking will be induced.

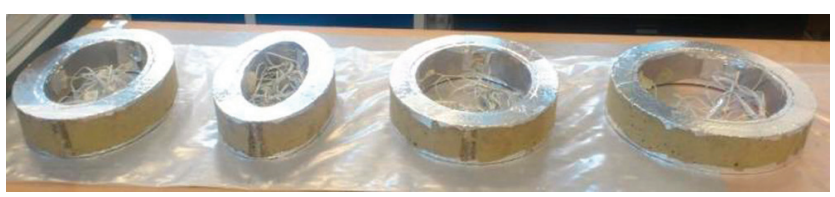

(a)

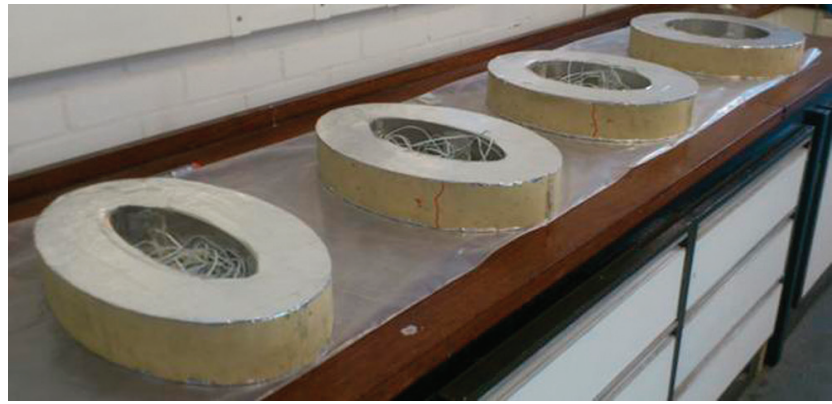

(b)

Figure 2. Sealed concrete ring specimens. (a) Sealed thin ring specimens. (b) Sealed thick ring specimens.

It should be reiterated here that this article is focused on investigating the mechanism of the proposed elliptical ring test method itself irrespective of materials. It is therefore necessary to investigate how the geometry or shape of the central restraining steel ring changes the degree of restraint to concrete surrounding it and consequently the age of cracking of concrete in a ring test. This was achieved by testing a series of circular and elliptical rings, thin and thick with different geometries, under restrained shrinkage. The proposed elliptical ring test was to mimic the circular ones recommended by AASHTO and ASTM as an index test for relative comparison purpose. In elliptical ring test, the outer transverse diameter of the restraining steel ring along the major axis remained constant as $2 a=300 \mathrm{~mm}\left(12^{\prime \prime}\right)$, but the corresponding conjugate diameter $2 b$ along the minor axis varied from $120 \mathrm{~mm}$ $\left(4.72^{\prime \prime}\right)$ to $250 \mathrm{~mm}\left(9.84^{\prime \prime}\right)$. In circular ring test, the outer diameter of the restraining steel ring remained constant as $2 a=300 \mathrm{~mm}$. All concrete rings were dried from their outer circumferential cylindrical surface with top and bottom surfaces sealed as shown in $\times a$ for sealed thin ring specimens and Figure 2(b) for sealed thick ring specimens, the same exposure condition as that recommended by AASHTO PP34-99 and ASTM 
C1581/C1581M-09a. With such exposure condition, shrinkage of concrete is uniform throughout the height of a ring specimen but not through its radial direction. All the circular and elliptical rings irrespective of their thicknesses had a height of $75 \mathrm{~mm}\left(3^{\prime \prime}\right)$, while the wall thickness of the central restraining steel ring was $12.5 \mathrm{~mm}\left(0.5^{\prime \prime}\right)$. It should be noted, however, that the restrained ring test is not intended to measure a fundamental material property of concrete. It can only be used for relative comparison purpose for assessing cracking potential of concrete and the effects of individual ingredients on cracking potential of concrete. It can also be used for aiding in the selection of concrete mixtures that are less likely to crack. Furthermore, no one ring geometry or external stimulus can be used to simulate all possible restrained conditions that may be encountered by concrete in the field. It is therefore of great importance that procedures, like those published by AASHTO and ASTM for circular ring tests, are developed to enable the elliptical ring test to be correctly interpreted for a variety of applications in the field.

\subsection{Restrained ring test}

The test setup typically comprises a restraining steel ring with four strain gages, each at the vertex of the ellipse, attached at mid-height of the inner cylindrical surface of the steel ring. The strain gage setup comprised a data acquisition system in a quarterbridge configuration, so that strain of the inner surface of the central steel ring is able to be continuously recorded throughout the test duration. Concrete was then cast around the steel ring, resulting into a ring specimen formed, after which it was immediately covered with a plastic sheet to prevent moisture loss with water sprayed on its top surface to keep a moisture environment for concrete. Afterward, the concrete ring specimens were cured under moisture environment in the laboratory for 1 day before their outer molds were stripped off. They were then immediately sealed with two layers of aluminum tape on the top and bottom surfaces to prevent undesirable moisture loss from these surfaces. The concrete ring specimen, together with the instrumented central restraining steel ring, was then moved into an environmental chamber with temperature of $23^{\circ} \mathrm{C}$ and $50 \%$ relative humidity, the drying environment specified by AASHTO PP34-99, for continuous curing with strain of the restraining steel ring being monitored throughout the test period. As concrete dries, the concrete ring tends to shrink with the steel ring restraining its shrinkage. Consequently, tensile stress is developed in the concrete ring along the circumferential direction, which may lead to cracking in the concrete if the tensile stress exceeds the tensile strength of concrete. Data acquisition from strain gages commenced the day when ring specimens were placed into the environmental chamber. Circumferential strain of the restraining steel ring was continuously monitored until crack initiated, which was captured and observed at the time when the measured strain showed considerable decrease. However, concrete rings were also examined by visual observation regularly twice per day from their exposed surface to monitor crack initiation and propagation. This secondary measure was used to compare the age of cracking obtained from visual observation with that detected by the strain data acquisition system.

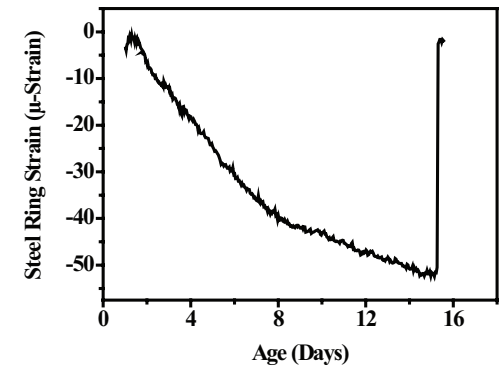

(a)

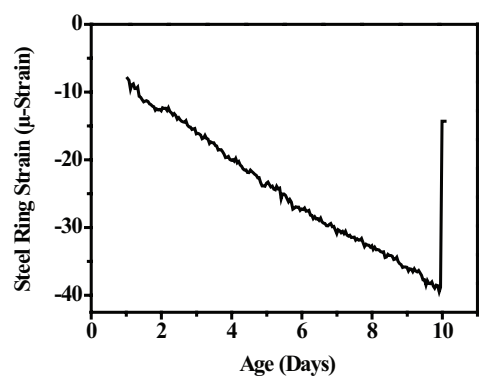

(b)

Figure 3. Measured strain with age from thin rings. (a) Circular ring $a=150 \mathrm{~mm}$. (b) Elliptical ring with $a \times b=150 \mathrm{~mm} \times 75 \mathrm{~mm}$.

\section{RESULTS AND DISCUSSION}

\subsection{Strain measurement and representation}

A typical example of measured strain from the restraining steel ring upon cracking initiation in concrete is presented in Figure 3 . It can be seen that the measurement indicates a gradual increase with age followed by a sudden and significant drop in strain. As concrete dries, its shrinkage increases with age. However, the increasing concrete shrinkage is restrained by the central restraining steel ring; thus an increasing pressure is imposed on the central steel ring by the surrounding concrete ring. Consequently, compressive stress is developed in the steel ring, which becomes greater and greater and is reflected by the increasing strain with age picked by the strain gages. Simultaneously, tensile stress is developed in the concrete ring, which also increases with age. Once the tensile stress exceeds the tensile strength of concrete, crack initiates and the pressure imposed on the central steel ring is released, resulting in stress, and thus strain suddenly drops in the central restraining steel ring. Effectively, the sudden drop in steel strain in one, two, 
three, or all four strain gages signaled crack initiation, which is the same technique as that recommended by ASTM C1581/C1581M-09a and AASHTO PP34-99 for crack detection in their standard circular ring test methods. Nevertheless, stress developed prior to the occurrence of visible crack can be attributed to the level of restraint, suggesting that there is a likelihood of steel ring restraining effect on crack initiation. Cracking can be detected immediately after it initiates because of the high sensitivity of strain gages. However, it takes time for crack to propagate throughout the concrete ring wall, and so it is believed that the sudden strain drop picked by strain gages indicates crack initiation, as strain gages are very sensitive, rather than the crack eventually propagating through the ring wall, which is supported by the crack pattern of rings observed from the experiment in this study, and this will be discussed in detail later. Cracking ages of a series of ring specimens determined by this technique are listed in Table 1. As aforementioned, concrete ring specimens were also visually examined at a regular basis alongside strain monitoring for cracking. But it should be noted that visual observation only gives the age when the crack penetrates through the wall of a concrete ring reaching its exposed outer circumferential surface and extending the full height of the concrete ring.

Table 1. Cracking ages (days) of concrete rings.

\begin{tabular}{clclc}
\hline $\begin{array}{c}\text { Ring geometry } \\
(\boldsymbol{a} \times \boldsymbol{b}) \mathbf{m m}^{\mathbf{2}}\end{array}$ & \multicolumn{2}{c}{ Thin rings } & \multicolumn{2}{c}{ Thick rings } \\
\hline $150 \times 150$ & 15 & 14 & - & - \\
$150 \times 125$ & 15 & 14 & 20 & 21 \\
$150 \times 100$ & 15 & 14 & 21 & 22 \\
$150 \times 75$ & 10 & 10 & 18 & 18 \\
$150 \times 60$ & 11 & 15 & 21 & 19 \\
\hline
\end{tabular}

\subsection{Effects of ring geometry on cracking in thin ring specimens}

It can be found from experimental results (see Table 1) that thin ring specimens with shorter minor axes usually cracked earlier than those with longer minor axes. For instance, the elliptical rings with $a \times b=150 \mathrm{~mm} \times 75 \mathrm{~mm}$ cracked on average at an age of 10 days compared with those with $a \times b=150 \mathrm{~mm} \times 125 \mathrm{~mm}$ and $150 \mathrm{~mm} \times 100 \mathrm{~mm}$, both of which cracked at the age of 14.5 days. It can also be seen that the cracking age of the circular ring with $a=150 \mathrm{~mm}$ and the elliptical rings with the geometry factor $a / b$, the ratio between the major and minor semi-axes, less than $2^{\prime \prime}$ this case, that those elliptical rings with $a \times b=150 \mathrm{~mm} \times 125 \mathrm{~mm}$ and $150 \mathrm{~mm} \times 100 \mathrm{~mm}$ were very close, that is, all at 14.5 days. The results further suggest that the ratio between the major and the minor semi-axes (i.e., geometry factor) of the elliptical ring is a contributing factor affecting the maximum circumferential tensile stress, and thus the cracking age of concrete rings when subjected to restrained shrinkage.

According to experimental results presented in Table 1, thin elliptical rings with appropriate geometry, in this case, the geometry factor $a / b>2$, can cause crack initiating earlier than the circular ones. They are therefore capable of accelerating ring tests to assess the relative likelihood of cracking of concrete mixtures. Consequently, as a result of the favorable geometrical effect, higher stress concentration occurred at specific positions in elliptical rings, which are usually close to the vertex along its major principal axis as expected and shown in Figure 4 in which the three thin elliptical rings with $b=60,75$, and $100 \mathrm{~mm}$ (from left to right) all cracked in the region of the major principal axis. Therefore, it can be concluded that ring geometry has a significant effect on cracking age and position of concrete in restrained elliptical rings.

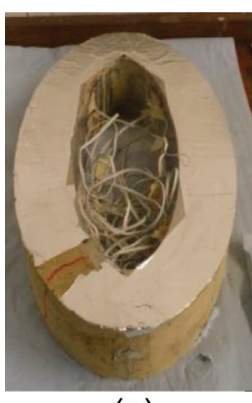

(a)

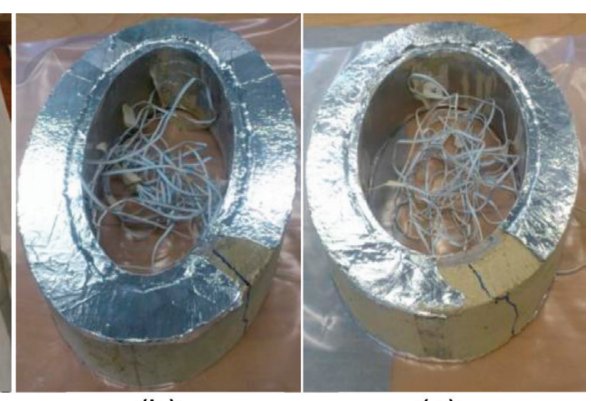

(b) (c)
Figure 4. Crack positions in thin elliptical rings. (a) $150 \mathrm{~mm} \times 60 \mathrm{~mm}$, (b) $150 \mathrm{~mm} \times 75 \mathrm{~mm}$, (c) $150 \mathrm{~mm} \times 100 \mathrm{~mm}$.

\subsection{Effect of ring wall thickness on cracking age and positions}

On the other hand, the thick ring specimens in this case with a wall thickness of $75 \mathrm{~mm}\left(3^{\prime \prime}\right)$, same as that recommended by AASHTO PP34-99, exhibited a different cracking behavior. Most thick ring specimens cracked at the age on or older than 20 days with the exception of the elliptical one with $a \times b=150 \mathrm{~mm} \times 75 \mathrm{~mm}$, which cracked at an age of 18 days on average as shown in Table 1 . Again all the ages shown in Table 1 were determined from strain measurement. Figure $5(\mathrm{a}-\mathrm{c})$ illustrates the cracks that were observed in thick ring specimens sealed at the top and bottom surfaces. These cracks were observed on either side of the outer circumferential surface along the minor axis and/or the major axis of the ring specimens with the geometry factor $a / b$ between 1.5 and 2.5 (i.e., of those rings with $a \times b=150 \mathrm{~mm} \times 100 \mathrm{~mm}$, $150 \mathrm{~mm} \times 75 \mathrm{~mm}$, and $150 \mathrm{~mm} \times 60 \mathrm{~mm}$ ), which will be discussed later. From Table 1, it can be seen that ring specimens with a thicker concrete wall cracked on average at an age of 20 days as compared with those 
with a thinner wall showing crack initiation on average at an age of 13.3 days under the same exposure and drying condition. This indicates, however, that, as the wall thickness of the rings increases, the potential for cracking is consequently reduced owing to the fact that all the ring specimens should have almost the same free shrinkage because of their closely identical exposed surface area-to-volume ratio (A/V). Furthermore, thicker specimens are less sensitive to the development of a similar sized initial crack (Hossain \& Weiss, 2004), implying that the crack driving energy (i.e., the energy required for crack growth) is lower for thicker specimens, which require a higher stress to cause a crack to propagate after it is initiated. This further indicates that ring wall thickness influences the behavior of concrete under restrained condition.

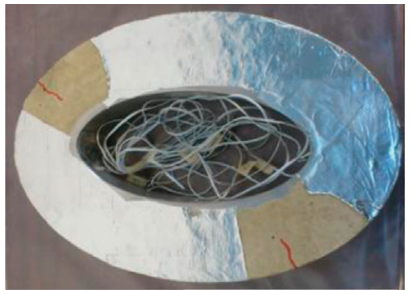

(a)

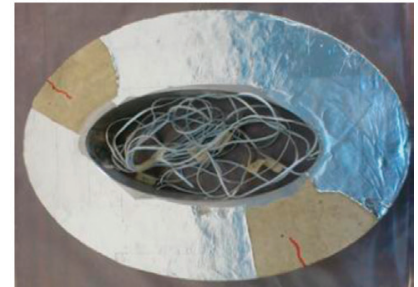

(b)

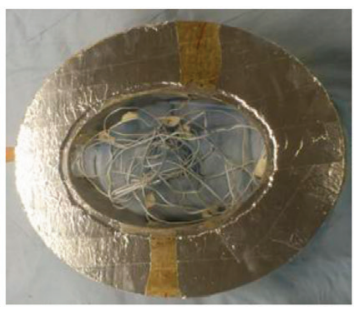

(c)

Figure 5. Crack positions in thick elliptical rings. (a) $150 \mathrm{~mm} \times 60 \mathrm{~mm}$. (b) $150 \mathrm{~mm} \times 75 \mathrm{~mm}$. (c) $150 \mathrm{~mm} \times 100 \mathrm{~mm}$.

\subsection{Crack initiation and propagation}

Cracks were carefully examined across the inner circumferential surface, alongside the top and bottom surfaces of the thin elliptical ring specimens after ring test was completed, and the aluminum tape and the central steel rings were stripped off the concrete ring. As shown in Figure $6(a, b)$, there were notable cracks in the thin elliptical ring with $a \times b=150 \mathrm{~mm} \times 125 \mathrm{~mm}$ on its inner circumferential surface along the major principal axis. In these figures, I and II highlight the cracks that initiated but without propagating through the concrete ring wall, while III illustrates more vividly the crack that eventually propagated through the concrete ring wall as shown in Figure 6(b).

Cracks were also observed in the thin elliptical ring specimens with $a \times b=150 \times 100,150 \times 75$, and $150 \times 60 \mathrm{~mm}^{2}$ (see Figure 4), which occurred very close to the vertex in the region where the maximum circumferential tensile stress is expected. However, with further observation, these cracks seen at the inner surface along the major principal axis did not manage to propagate through the concrete ring wall to reach the outer circumferential surface, and neither did it appear across the top surface of the concrete ring specimen as is usually the case when a crack propagates. It is also possible that the crack actually does not propagate fully through the concrete ring wall. In the course of the test, cracking could not be observed from the outer circumferential surface of the ring as they did not propagate through to the outer surface as shown in Figure 7(a).

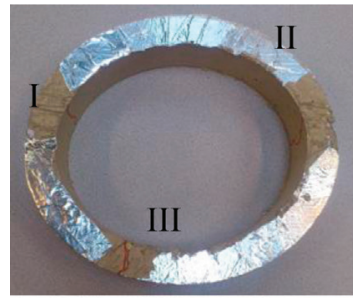

(a)

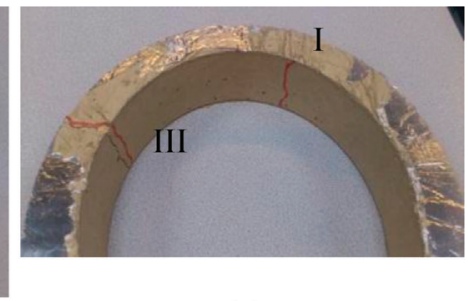

(b)
Figure 6. Final crack pattern of a thin ring $(a \times b=150 \mathrm{~mm} \times 125 \mathrm{~mm})$. (a) Overview. (b) Through and non-through cracks.

It was found from this study that cracks were usually noticed by visual observation 2 days after being detected by strain gages for thick ring specimens. In comparison, cracks were visually observed only 1 day after crack initiation as detected by strain gages for thin ring specimens. This further ascertained that the abrupt drop in measured strain detected by strain gages indicated that crack initiated rather than propagated throughout the ring wall because a crack can only be visually observed after propagation takes place through the wall of the ring specimen, and subsequently, it takes time for the crack to propagate throughout the ring wall after it initiates. In this case, it took longer for a crack to propagate through the wall of a thick ring, and hence, longer to be visually observed after its initiation was detected by strain measurement. In the case of thin rings, due to geometry effect, stress concentration may take place at a specified position, which is usually close to the vertex along the major axis at the inner circumferential surface of an elliptical concrete ring. Therefore, cracks are more likely to initiate at these regions. Subsequently, other cracks may initiate and propagate at areas along the minor axis further away from the vertex as a result of stress redistribution after initial cracks occur. Crack propagation in concrete usually experiences two stages, stable and unstable, after crack inception. The stable stage infers that crack can only propagate under increasing driving energy, and this energy/force in ring test is provided by the shrinkage that occurs in concrete. As concrete matures, shrinkage increases leading to an increased driving 
energy, and hence, crack propagation. As observed, crack originally initiated at $A$ and $B$ along the major axis [see Figure 7(a)] but ceased to propagate due to reduced crack driving energy. However, as a result of increased circumferential tensile stress redistribution in other regions of the concrete ring, a new crack was generated and subsequently propagated at $\mathrm{C}$. This behavior may account for crack propagation throughout the wall of the concrete ring, which later appeared at the outer circumferential surface of the thin elliptical ring with $a \times b=150 \times 125$ and $150 \times 100 \mathrm{~mm}^{2}$ as shown in Figures 6 and 7(a). Eventually the crack was observed visually at $C$ and became the only crack that managed to propagate through the wall of the ring specimen, while $A$ and $B$ on either side of the major axis initiated but failed to propagate through the wall thickness. Conversely, as a result of the increased stress in thicker specimens, which was believed to be developed in the radial direction of the ring due to the presence of moisture gradient, Weiss and Shah (2002) proposed that crack may actually initiate at the outer circumferential surface and propagate toward the inner one in thick rings, which was confirmed in this study by the results of thick elliptical rings with $a \times b=150 \times 75,150 \times 100$, and $150 \times 125 \mathrm{~mm}^{2}$ as shown in Figures $5(b, c)$ and $7(b)$. Those rings were observed to crack at two opposite positions along their outer circumference and propagated toward the inner circumference of the rings on their top and bottom surfaces (i.e., surfaces sealed during test). These cracks extended through the full height of the rings on their outer circumferential surface based on which the ring test was stopped. However, they were discovered not managing to propagate through the concrete ring wall after the test was stopped, and the aluminate tape sealing the top and bottom surfaces of the ring specimens was stripped off.

\section{CONCLUSIONS}

This article explored the use of elliptical rings to assess cracking potential of concrete and the effect

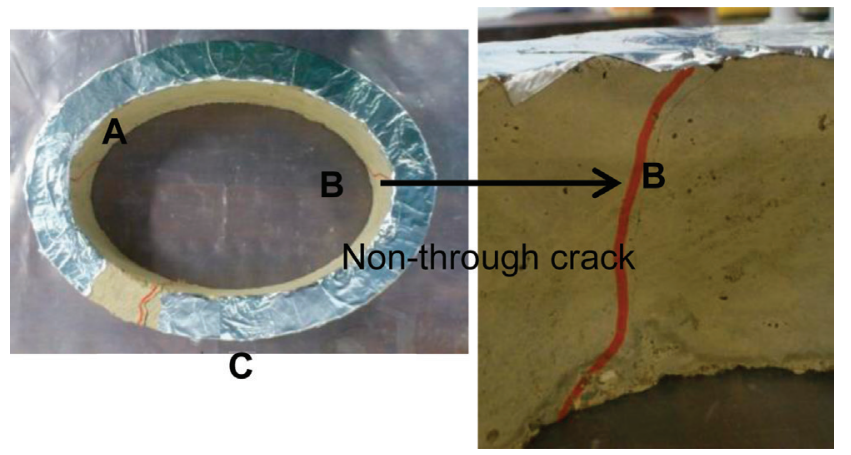

of ring geometry, including ring wall thickness on the cracking behavior of ring specimens under restrained shrinkage. Experimental efforts included using elliptical ring specimens to provide information for a simple geometry to enable an improved understanding of shrinkage cracking and better evaluation of cracking tendency of concrete. Based on the experimental results, the following conclusions were drawn:

1. Thin elliptical rings, with a wall thickness of $37.5 \mathrm{~mm}\left(1.5^{\prime \prime}\right)$ as recommended by ASTM C1581/C1581M-09a, can increase the likelihood of crack initiation in concrete specimens at expected positions and are seen to crack at an earlier age with a decrease in minor principal axis.

2. The abrupt drop observed from steel strain recorded during restrained ring test indicated crack initiation and was usually 1 day for thin ring specimens and 2 days for thick ring specimens after visible cracking was observed.

3. In restrained thin elliptical rings, crack initiated at the vertices on the major axis of the inner elliptical circumference and propagated from the inner circumference to the outer one. However, in restrained thick elliptical rings, crack initiated at the two vertices either on the minor axis or on the major axis of the outer elliptical circumference and propagated to the inner one.

4. Thin elliptical rings were observed to have cracks on the inner circumferential surface of the concrete ring along the major principal axis as would have been expected but without propagating through the ring wall. As such, it is possible that some cracks initiate but do not necessarily propagate fully through the concrete ring wall.

5. For the ring specimens with a thin concrete wall, the elliptical rings with the geometry factor $a / b=2$ is recommended to replace circular rings for restrained shrinkage test, which can increase cracking sensitivity so that concrete ring can
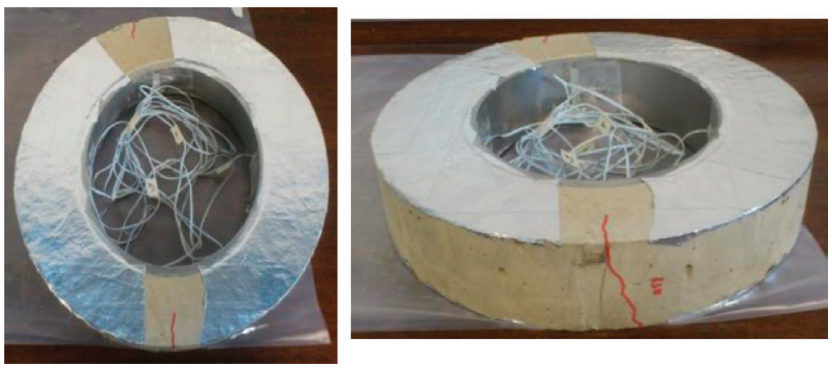

(b)

(a)

Figure 7. Crack positions in thin and thick rings. (a) Thin ring with $a \times b=150 \mathrm{~mm} \times 100 \mathrm{~mm}$. (b) Thick ring with $a \times b=150 \mathrm{~mm} \times 125 \mathrm{~mm}$ 
crack in a shorter period for faster assessment of cracking potential of a large amount of concrete mixtures.

6. Finally, it is revealed further that, as the wall thickness of a concrete ring is increased, the potential for cracking is consequently reduced since the thicker walled specimens are less sensitive to small cracks (i.e., a lower crack driving energy is experienced).

\section{ACKNOWLEDGMENTS}

The financial support from Engineering and Physical Science Research Council (EPSRC) UK under the grant EP/I031952/1 and EPSRC Doctoral Training Account allocation to Brunel University is greatly appreciated.

\section{REFERENCES}

Bentur, A., \& Kovler, K. (2003). Evaluation of early age cracking characteristics in cementitioussystems. Materials and Structures, 36(3), 183-190.

Branch, J., Rawling, A., Hannant, D. J., \& Mulheron, M. (2002). The effects of fibres on the plastic shrinkage cracking of high strength concrete. Materials and Structures, 35(247), 189-194.

Briffaut, M., Benboudjema, F., Torrenti, J. M., \& Nahas, G. (2011). A thermal active restrained shrinkage ring test to study the early age concrete behaviour of massive structures. Cement and Concrete Research, 41, 56-63.

He, Z., Zhou, X. M., \& Li, Z. J. (2004). New experimental method for studying early-age cracking of cement-based materials. ACI Materials Journal, 101(1), 50-56.

Hossain, A. B., \& Weiss, J. (2004). Assessing residual stress development and stress relaxation in restrained concrete ring specimens. Cement and Concrete Composites, 26(5), 531-540.

Hossain, A. B., \& Weiss, J. (2006). The role of specimen geometry and boundary conditions on stress development and cracking in the restrained ring test. Cement and Concrete Research, 36(1), 189-199.

Li, Z. J., Qi, M., Li, Z. L., \& Ma, B. G. (1999). Crack width of high-performance concrete due to restrained shrinkage. Journal of Materials Civil Engineering ASCE, 11(3), 214-223.

Mokarem, D. W., Weyers, R. E., \& Lane, D. S. (2005). Development of a shrinkage performance specifications and prediction model analysis for supplemental cementitious material concrete mixtures. Cement and Concrete Research, 35(5), 918-925.

Moon, J. H., Rajabipour, F., Pease, B., \& Weiss, J. (2006). Quantifying the influence of specimen geometry on the results of the restrained ring test. Journal of ASTM International, 3(8), 1-14.

Moon, J. H., \& Weiss, J. (2006). Estimating residual stress in the restrained ring test under circumferential drying. Cement and Concrete Composites, 28(5), 486-496.

Passuello, A., Moriconi, G., \& Shah, S. P. (2009). Cracking behaviour of concrete with shrinkage reducing admixtures and PVA fibers. Cement and Concrete Composite, 31(10), 699-704.

See, H. T., Attiogbe, E. K., \& Miltenberger, M. A. (2003). Shrinkage cracking characteristics of concrete using ring specimens. ACl Materials Journal, 100(3), 239-245.

Shah, S. P., Weiss, W. J., \& Yang, W. (1998). Shrinkage cracking - Can it be prevented. Concrete International, 20(4), 51-55.

Tongaroonsri, S., \& Tangtermsirikul, S. (2009). Effect of mineral admixtures and curing periods on shrinkage and cracking age under restrained condition. Construction and Building Materials, 23(2), 1050-1056.

Turcry, P., Loukili, A., Haidar, K., Pijaudier-Cabot, G., \& Belarbi, A. (2006). Cracking tendency of self-compacting concrete subjected to restrained shrinkage: Experimental study and modeling. Journal of Material Civil Engineering ASCE, 18(1), 46-54.

Weiss, W. J., \& Shah, S. P. (2002). Restrained shrinkage cracking: The role of shrinkage reducing admixtures and specimen geometry. Materials and Structures, 35(246), 85-91.

Weiss, W. J., Yang, W., \& Shah, S. P. (2000). Influence of specimen size/geometry on shrinkage cracking of rings. Journal of Engineering Mechanics ASCE, 126(1), 93-101. 